\title{
Student Database System for Higher Education: A Case Study at School of Public Health, University of Ghana
}

\author{
Wisdom Kwami Takramah ${ }^{1}$, Wisdom Kwasi Atiwoto ${ }^{2}$ \\ ${ }^{1}$ Department of Epidemiology and Biostatistics, School of Public Health, University of Health and Allied Sciences, Ho, Ghana \\ ${ }^{2}$ Department of Biostatistics, School of Public Health, University of Ghana, Accra, Ghana
}

Email address:

takramah@uhas.ed.ug (W. K. Takramah)

\section{To cite this article:}

Wisdom Kwami Takramah, Wisdom Kwasi Atiwoto. Student Database System for Higher Education: A Case Study at School of Public Health, University of Ghana. American Journal of Software Engineering and Applications. Vol. 4, No. 2, 2015, pp. 23-34.

doi: 10.11648/j.ajsea.20150402.11

\begin{abstract}
The success of any organization such as School of Public Health, University of Ghana hinges on its ability to acquire accurate and timely data about its operations, to manage this data effectively, and to use it to analyze and guide its activities. Integrated student database system offer users (Student, Registrar, HOD) with a unified view of data from multiple sources. To provide a single consistent result for every object represented in these data sources, data fusion is concerned with resolving data inconsistency present in the heterogeneous sources of data. The main objective of this project is to build a rigid and robust integrated student database system that will track and store records of students. This easy-to-use, integrated database application is geared towards reducing time spent on administrative tasks. The system is intended to accept process and generate report accurately and any user can access the system at any point in time provided internet facility is available. The system is also intended to provide better services to users, provide meaningful, consistent, and timely data and information and finally promotes efficiency by converting paper processes to electronic form. The system was developed using technologies such as PHP, HTML, CSS and MySQL. PHP, HTML and CSS are used to build the user interface and database was built using MySQL. The system is free of errors and very efficient and less time consuming due to the care taken to develop it. All the phases of software development cycle are employed and it is worthwhile to state that the system is very robust. Provision is made for future development in the system.
\end{abstract}

Keywords: Relational Database, Interoperability, Database Management System, phpMyAdmin, MySQL Server, Data Redundancy, Middleware

\section{Introduction}

The registrar of the School of Public Health, University of Ghana is responsible for handling student information and gathering them during enrollment. This information includes each student's background information, student medical history, courses taken student attendance at lectures grades, performance record, and other information needed by the school.

Today, the success of School of Public Health, University of Ghana depends on its ability to acquire accurate and timely data about its operations, to manage this data effectively, and to use it to analyze and guide its activities. Phrases such as the information superhighway have become ubiquitous, and information/data processing is a rapidly growing multibillion dollar industry.
Several forms and reports are used in day to day processing of results. A database can integrate these several components hence resulting in improved and more efficient operations (Greenwald et al., 2005; Connolly and Begg, 2004).

Student Database System deals with all kind of student details, academic related reports, college details, course details, curriculum, batch details and other resource related details too. It tracks all the details of a student from the day one to the end of his course which can be used for all reporting purpose, tracking of attendance, progress in the course, completed semesters years, coming semester year curriculum details, exam details, project or any other assignment details, final exam result; and all these will be 
available for future references too.

\subsection{Problem Statement}

Information plays a vital role in the development and growth of every organization. Currently, the various departments manage student information independently in their own ways. There are no common, standardized process and program for capturing, processing and storing student's information. This has kept student information disintegrated in different departments and information provided to the various departments by the students is characterized with discrepancies.

The various departments have systems in place to store and process student data but the systems are not able to talk to each other (Interoperability). This makes it difficult for the registrar to collate information of students across departments. For instance, if the registrar wants information about students with respect to their academic performance urgently, he must go to all the departments and collect the required data. On occasions where the department is not able to produce the needed information immediately, the business or activity at that particular time would come to a standstill. On the other hand, time is being wasted going round the various departments to solicit data. This situation is very frustrating and impedes smooth operations and decision making process.

One of the policies of School of Public Health, for that matter University of Ghana is the fact that students must not fail in three or more courses. Referrals in three or more courses will warrant expulsion from the school. The current information system is incapable of providing students with exams result before courses are registered for the next semester.

A past student who needs a transcript will have to travel all the way to the school before he could access it because the current system is so weak to the extent that it is unable to provide this document online.

The problems facing the current manual system are data redundancy, difficult to update and maintain, inconsistent data, insecurity, difficult to impose constraints on various data file and difficult to backup.

It is against this backdrop that automated Student Database System is being developed to address the problems catalogued above.

\subsection{Project Objective}

The main objective is to develop a robust Student Database Management System for School of Public Health.

Specific Objectives

- To identify the problems involved in the implementation of the current student information system;

- To develop a database system that allows the registrar to list and update students information;

- To develop a system that permits authorized student to view their result online;
- To develop the prototype of an integrated Student Database System that can be implemented.

\subsection{Purpose of Project}

The proposed system is intended to make life easy. The main purpose of the project is to build an integrated student database system to facilitate easy access of records of students across departments. The Student Database System will allow the registrar of School of Public Health, Legon to edit, update and list personal and academic details of students. It will also enhance efficient management of student's information.

The proposed system is also intended to allow students to view their results on line. This will go a long way to help students decide on what courses to register.

\subsection{Scope}

The proposed system is intended to manage specific information of students such as personal details, course details and exam details etc. It is not Student Information Management System which has a broader application. It is only a part of Student Information Management System.

This project when completed will provide comprehensive Student Database System for School of Public Health, University of Ghana. The system should be able to capture, validate, sort, classify, calculate, summarize, store, retrieve, reproduce and communicate operational data. Student Database System will store semester details, course details, department details and all the details of students including their background information, educational qualifications and personal details etc.

The proposed system will have the following features:

- Login module: Login module will help in authentication of user accounts. Users who have valid login id and password can only login into their respective accounts;

- Search module: This model allows one to search for a particular student or group of students using search criteria such as name of student, Index number, course code etc;

- Registration Module and Account Management: This module will help the student get registered from anywhere if internet is present .This module will really simplify the task of the manual registration. Also after successful registration the user can update information and change their password as and when required;

- User Management: This module will help the registrar in enabling/disabling a user account and updating user information as required.

\section{Literature Review}

A project on Student Information Management system which was carried out by Kapil Kaushik Ankur Agarwal Tushar Somani, an IT student of Institute of Engineering and Technology, Maharishi provides a simple interface for 
maintenance of student information. It can be used by any educational institute or colleges to maintain records of students easily. Achieving this objectives is difficult using a manual system as the information is scattered, can be redundant and collecting relevant information can be very time consuming. All these problems are solved using this project. Throughout the project the focus has been on presenting information in an easy and intelligible manner. The project is very useful for those who want to know about Student Information Management Systems and want to develop software/websites based on the same concept. The project provides facilities like on line registration and profile creation of student thus reducing paper work and automating the records generation process in an educational institution.

The goal of this chapter is to explain the theory of database management system development which will be applied in the development of student database management system for school of public health, University of Ghana. The following issues will be presented respectively.

1. Integrated information system

2. Database and DBMS

3. Student records/data management

4. Web technology

5. Conclusion

This will give an insight into the project area and help to get information that will enhance the development of the student database management system.

\subsection{Integrated Information System}

Integrated Information Systems offer users with a unified view of heterogeneous data sources. To provide a single consistent result for every object represented in these data sources, data fusion is concerned with resolving data inconsistencies present in the sources. Querying the heterogeneous data sources, combining the results, and presenting them to the user is performed by the integration system.

When multiple sources are to be integrated into a single and consistent view, at least the following three steps need to be performed:

- One needs to identify corresponding attributes that are used to describe the information items in the source. The result of this step is a schema mapping that is used to transform the data present in the sources into a common representation;

- The different objects that are described in the data sources need to be identified and aligned. In this way, using duplicate detection techniques, multiple, possibly inconsistent representations of some real world objects are found;

- As a last step, the duplicate representations need to be combined and fused together into a single representation while inconsistencies in the data need to be resolved;

There are two main kinds of inconsistencies in data integration:

- First, there are schematic inconsistencies between sources, tables not having the same attributes, attributes meaning the same concept but having a different name, or stored data in a different structure and;

- Conflicts is another kind of data inconsistency

There are two types of conflicts in data integration; Uncertainties and contradictions

Uncertainty is a conflict between a non-null value and one or more null values that are used to describe the same property of an object. Usually it occurs as a result of missing information. Null values present in tables can have different meanings. Three interpretations of null values can be distinguished as follows:

1. Value unknown: The value exist but whoever entered the data did not know it

2. Value inapplicable: The corresponding property is not applicable for the object represented by this tuple.

3. Value withheld: The data exist but we are not allow to see it.

The other type of conflicts is contradiction. It is the conflict between two or more different non-null values that are used to describe the same property of an object. An example is the case if two or more data sources provide two or more different values for the same attribute on the same object.

One good reason for regarding uncertainty as a special case of conflict is the fact that it is easier to deal with uncertainty than contradiction.

Several forms and reports are used in day to day processing of documents. A database can integrate these several components hence resulting in improved and more efficient operations (Greenwald et al., 2005; Connolly and Begg, 2004).

\subsection{Database and Database Management System}

A database is an integrated collection of data, usually so large that it has to be stored on secondary storage devices such as disks or tapes. This data can be maintained as a collection of operating system files, or stored in a DBMS (database management system).

A Database Management System (DBMS) is computer software designed for the purpose of managing databases based on a variety of data models. A DBMS is a complex set of software programs that controls the organization, storage, management, and retrieval of data in a database. DBMS are categorized according to their data structures or types, sometime DBMS is also known as Database Manager. It is a set of prewritten programs that are used to store, update and retrieve a Database (Gerald C. Okereke, 2009).

When a DBMS is used, information systems can be changed much more easily as the organization's information requirements change. New categories of data can be added to the database without disruption to the existing system. Organizations may use one kind of DBMS for daily transaction processing and then move the detail onto another computer that uses another DBMS better suited for random inquiries and analysis.

Database servers are specially designed computers that 
hold the actual databases and run only the DBMS and related software. Database servers are usually multiprocessor computers, with RAID disk arrays used for stable storage. Connected to one or more servers via a high speed channel, hardware database accelerators are also used in large volume transaction processing environments.

Advantages of DBMS

- Improved strategic use of corporate data

- Reduced complexity of the organization's information systems environment

- Reduced data redundancy and inconsistency

- Enhanced data integrity

- Application-data independence

- Improved security

- Reduced application development and maintenance costs

- Improved flexibility of information systems

- Increased access and availability of data and information

- Logical \& Physical data independence

- Concurrent access anomalies.

- Facilitate atomicity problem.

- Provides central control on the system through DBA.

\subsection{Student Records/Data Management}

According to student records manual prepared by University of South Florida (office of the registrar) the creation and maintenance of records relating to the students of an institution are essential to:

- managing the relationship between the institution and the student;

- providing support and other services and facilities to the student;

- controlling the student's academic progress and measuring their achievement, both at the institution and subsequently;

- providing support to the student after they leave the institution.

In addition, student records contain data which the institution can aggregate and analyze to inform future strategy, planning and service provision.

A student is an individual who is registered for a university credit course or program.

A student record/data contains information directly related to a student, which means that the record is personally identifiable. Personal identifiers that relate a record to a student include student name, student ID, student address, parent/family member names, and a list of personal characteristics. Student records could be maintained in multiple media including handwriting, print, microfilm/fiche, computer's main memory, magnetic tape, cassette, disk or diskette.

Student records/data may be presented by the student, submitted on behalf of the student, or created by the University. These records are used to assist offices in their support of basic institutional objectives and to document student progress and achievement in the educational process of the University.

Educational institutions and agencies are required to conform to fair information practices. This means that persons who are subjects of data systems (i.e., students at an institution) must:

- be informed of the existence of such systems

- have identified for them what data about them are on record,

- be given assurances that such data are used only for intended purposes

- be given the opportunity to request an amendment or correction to their record and

- be certain that those responsible for data systems take reasonable precautions to prevent misuse of the data.

\subsection{Web Technology}

The web is a hypermedia-based system that provides a means of browsing information on the Internet in a nonsequential way using hyperlinks. The web is a compelling platform for the delivery and dissemination of data-centric, interactive applications. The web's ubiquity provides global application availability to both users and organizations. Because the architecture of the web has been designed to be platform-independent, it has the potential to significantly lower deployment and training cost. Organizations are now rapidly building new database applications or reengineering existing ones to take full advantage of the web as a strategic platform for implementing innovative business solutions, in effect becoming web-centric organization.

The World Wide Web (web for short) provides a simple point and click means of exploring the immense volume of pages of information residing on the Internet (Berners-Lee 1992; Berners-Lee et al.. 1994). Information on the web is presented on the web pages which appear as a collection of text, graphic, pictures, sound and video.

\subsection{Conclusion}

Finally, since the data generated in day to day transactions by School of Public Health increase geometrically according to the registrar, it is worthwhile and holistic to develop robust student database management system for the school to hold the large amount of data that is generated. The proposed system, SDMS, should be able to stand the test of time because student records should be kept as long as is necessary to:

- fulfill and discharge the contractual obligations established between the institution and the student, including the completion of any non-academic disciplinary action;

- provides information on the academic career and achievements of the student to employers, licensing/regulatory bodies and other organizations, as well as to the student as part of their lifelong learning record.

The information gathered whilst reviewing existing literature on student information management system has 
been very useful in the development of the proposed system.

The project when completed will provide an efficient way to store and organize data than spreadsheet. It will also serve as a centralized facility that can easily be modified and quickly shared among multiple users. The proposed system will have a well-designed interface that allows users to interact with the system via internet connection and a web browser.

\section{Methodology}

This Chapter gives a brief description of the methodology used to develop the proposed system. The main methodology involves feasibility study, data collection, system analysis and design, developing and implementing Student Database Management System. The data considered necessary to build the system were collected and analyzed. The methodology is very important to ensure that the new system would give benefits to the school.

\subsection{Data Collection}

The required data including department details, course details, student personal details, semester details, exam details etc. were collected. The data collected would help identify attributes, relationships, classes, entities/objects that describe, relate and interact with the system.

The data collection tools and techniques that were used are as follows:

\subsubsection{Interview}

Interview is a powerful tool for data gathering since it allows the interviewer to probe and clarify a number of issues. Face to face interview was used to interact with the registrar and the users of the proposed system to obtain the data required for the database management system.

\subsubsection{Analysis of Current Student Information System}

Purposes of the current Student Information System analysis are:

- To identify problems inhibiting the current student information system

- To know how data is being managed

- To examine the methods used in current student information system

- To know the data flow in the system

The current student information system was studied to get some useful information for developing an effectual Student Database System. Currently, the various departments manage student information independently in their own ways. There are inadequate common, standardized process and program for capturing, processing and storing student's information. This has kept student information fragmented in different departments and information provided to the various departments by the students is characterized by discrepancies.

The various departments have systems in place to store and process student data but the systems are not able to talk to each other (Interoperable). This makes it difficult for the registrar to collate information of students across departments. On the other hand, students are unable to view their result online for them to know whether they are continuing the program and also to know the courses they can register for the next semester.

\subsection{Proposed System will Consist of the Following Modules}

\subsubsection{Security}

The Student database management system will ensure that the data are secured by assigning a unique password and username. The registrar and student of school of public health will be allowed to access the system. The administrator account can be accessed by the registrar and student account can be accessed by the student using their registration number. The respective student database management system will be encoded by the system administrator. In case the user forgot their password, the system offers a forgot password module in which the user can select this menu and answer the secret question or code that the user only knows. A log component that chronicles information about users who login and logout will be provided.

\subsubsection{Registration and Verification}

This module allows users to enter the required information including username, password, first name, last name, address, birth date and position. This will serve as the personal record of the users. The system will verify this information first before the authorized users can enter the system. Duplication of users in the system will completely be eliminated due to a very rigid verification method.

\subsection{Functions of the Proposed System}

Three different user categories will be allowed access to the system

1 registrar who can view and edit the details of any students

2 head of department who can add courses, departments and exams details as well as edit and delete details

3 students who can view and modify their details .

The proposed system will provide the following features to the registrar:

- The registrar can login into the system and execute any of the available tasks;

- Can enable/disable student;

- Can edit student information in the database;

- Can make search for a specific student;

- Can access all the details of the student.

The features that are available to the student are:

Student can login into the system and can perform any of the available options.

- Can view his/her personal details.

- Can edit his/her personal details

- Can upload his/her project topics.

- Can upload his/her image. 


\subsection{Specific Requirement}

Use-Cases are a scenario based technique in the Unified Modelling Language which identify the actors in an interaction and which describe the interaction itself. Use cases were used to describe all possible interactions of the entities with the system.

Organizing Student Records Flow of Event

The registrar is mandated to manage student records

Use Case: Login in to the SDMS

Summary: This use case is used when the registrar wants to access the SDMS to add/update the personal details of the student.

Actors: Registrar

Pre-condition: Registrar's account must be active on the system

Main Flow:

MF-001: The system displays the login page and prompts the registrar for the Login_Id and Password

MF-002: The registrar provides values for the Login_Id and password fields.

MF-003: The registrar hits the submit button

MF-004: The system verifies (authenticates) the password and sets the registrar's authorization. (AF-1.1, AF-1.2)

MF-005: The Administrator is given access to the SDMS to perform his tasks.

ALTERNATE FLOW 1.1 (AF-1.1):

AF-1.1.1: The registrar enters invalid LoginId and password then he will not be allowed to enter the system

AF-1.1.2: Go to MF-002

ALTERNATE FLOW 1.2 (AF-1.2):

AF- 1.2.1: The system fails to authenticate user after a default of 2 continuous unsuccessful attempts

ALTERNATE FLOW 1.3 (AF-1.3):

AF- 1.3.1: The system fails to authenticate user after a default of 3 continuous unsuccessful attempts

AF-1.3.2: The system deactivates user account

AF-1.3.3: System notifies the user of account deactivation via a system prompt

AF-1.3.4: The user acknowledges system prompt by clicking OK button

Post-Condition: The registrar login successfully

Use Case Report- Register student on SDMS

Use-case: Login into the SDMS

Goal: Gain access to the website

Summary: This use case is used when the student wants to access the web site

Preconditions: The registrar must enable the particular student onto the website in order for this use case to begin.

Main Flow:

MF-001: The system displays the login page and prompts the student for the Login_Id and Password.

MF-002: The student provides values for the Login_Id and password fields.

MF-003: The student hits the submit button

MF-004: The system verifies (authenticates) the password and sets the student's authorization. (AF-1.1, AF-1.2)
MF-005: The student is given access to the SDMS to perform his tasks.

ALTERNATE FLOW 1.1 (AF-1.1):

AF-1.1.1: The student enters invalid LoginId and password then he will not be allowed to enter the system

AF-1.1.2: Go to MF-002

ALTERNATE FLOW 1.2 (AF-1.2):

AF- 1.2.1: The system fails to authenticate user after a default of 2 continuous unsuccessful attempts

AF-1.2.2: The system triggers image verification for any further login attempts

AF-1.2.2: Go to MF-002

ALTERNATE FLOW 1.3 (AF-1.3):

AF- 1.3.1: The system fails to authenticate user after a default of 3 continuous unsuccessful attempts

AF-1.3.2: The system deactivates user account

AF-1.3.3: System notifies the user of account deactivation via a system prompt

AF-1.3.4: The user acknowledges system prompt by clicking OK button

Post-Condition: The student login successfully

\subsection{Non-Functional Requirement}

\subsubsection{Safety Requirement}

Operating system failure or virus can cause the database to crash at any point in time. Database backup is very important.

\subsubsection{Security Requirement}

Secured database system was developed. There are three categories of users namely registrar, faculty and student who would view either all or some specific information from the database. Depending upon the category of user the access rights are decided.

This means that if the user is a registrar then he can be able to modify the data, append etc. Other users can only retrieve information.

\subsubsection{Performance Requirement}

The proposed system would serve as the main performance system which will go a long way to help School of Public Health manage and maintain the database of student. All specified requirements are expected to be met by the proposed database.

\subsection{System Design}

The purpose of the system design phase was to develop a clear blueprint that would satisfy all documented requirement for the system.

The overall system design objective was to provide an efficient, modular design that will reduce the system's complexity, facilitate change and result in an easy implementation. This blueprint provided interface design models that are consistent, user friendly and will provide straightforward transition through the various system functions. 


\subsubsection{System Architectural Design}

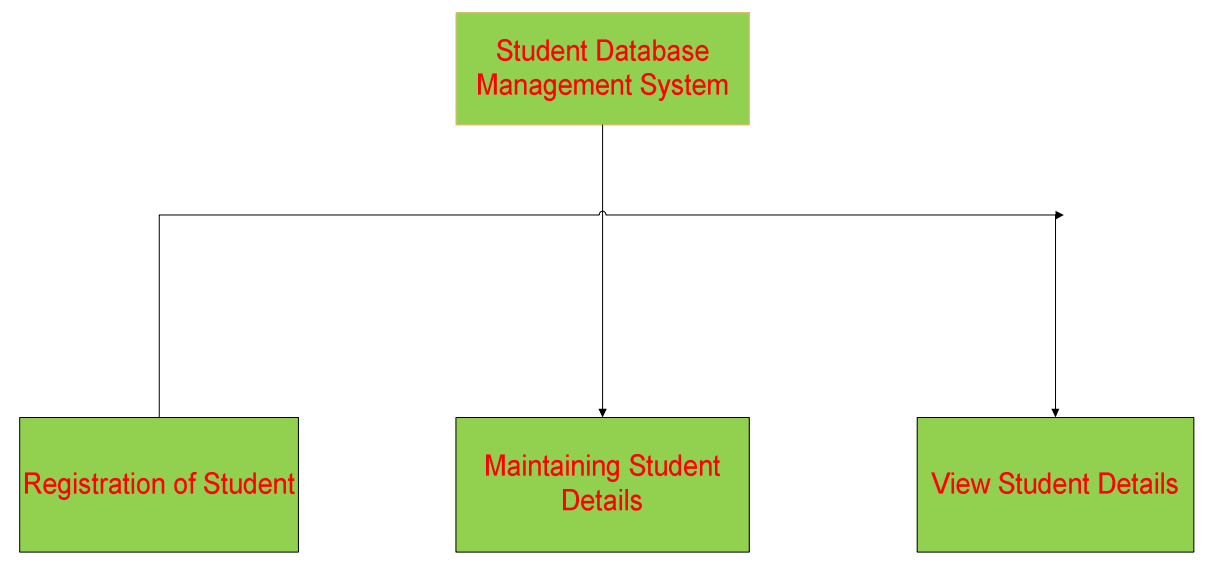

Fig 3. Architecture Diagram

The SDS is system which has major components such as student detail, department detail and course detail. One of the available options is selected as an input to the system. The system acts and the rest of the functions are performed respectively based on the input by the user. The registrar has automatic access right to manage and maintain student detail. The student can only view their details.

\subsubsection{Data Design}

Entity Relationship Diagram

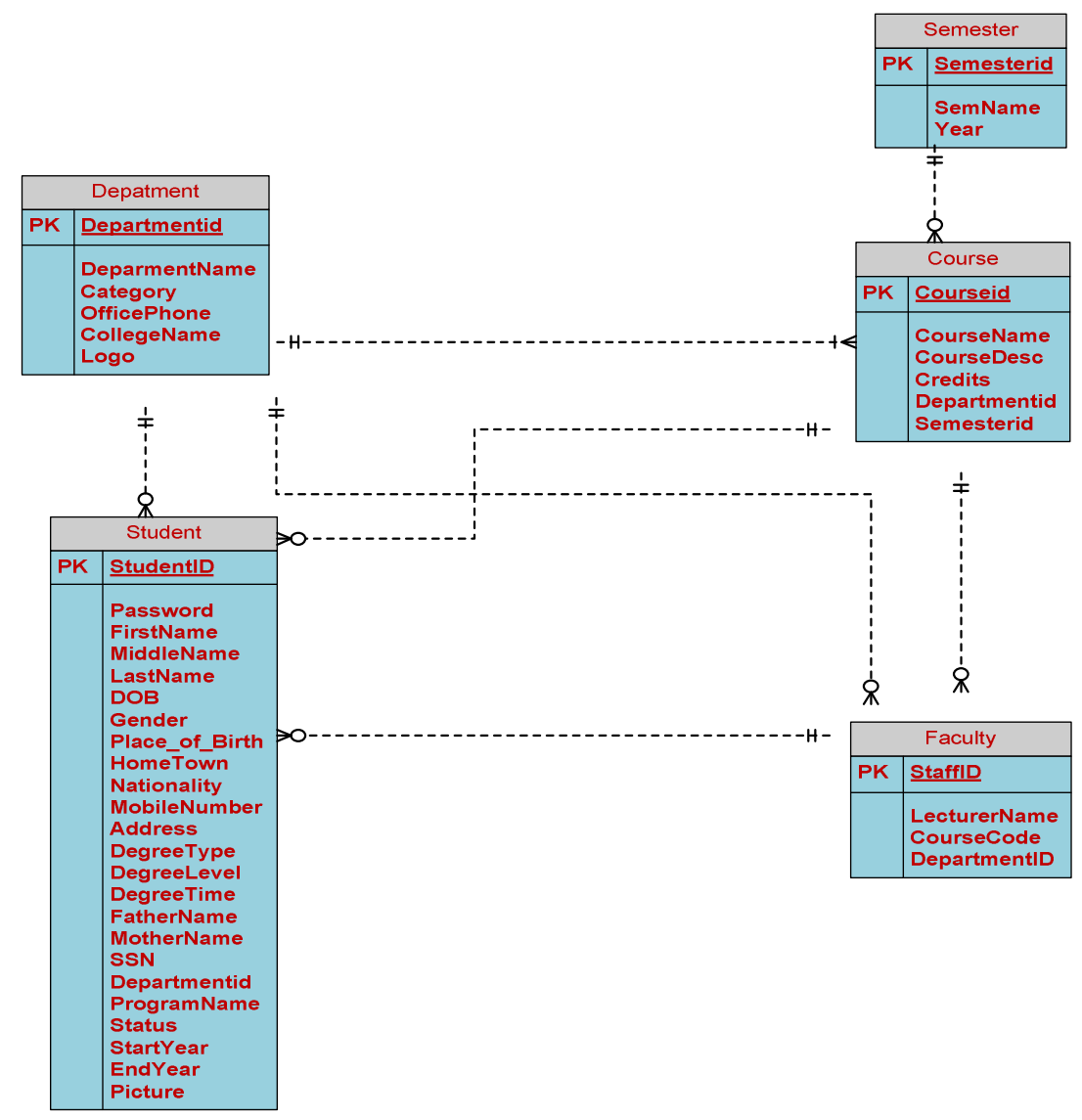

Fig 3.1. Entity Relationship Diagram

\subsubsection{Functional Design Description}

Dataflow Diagram 


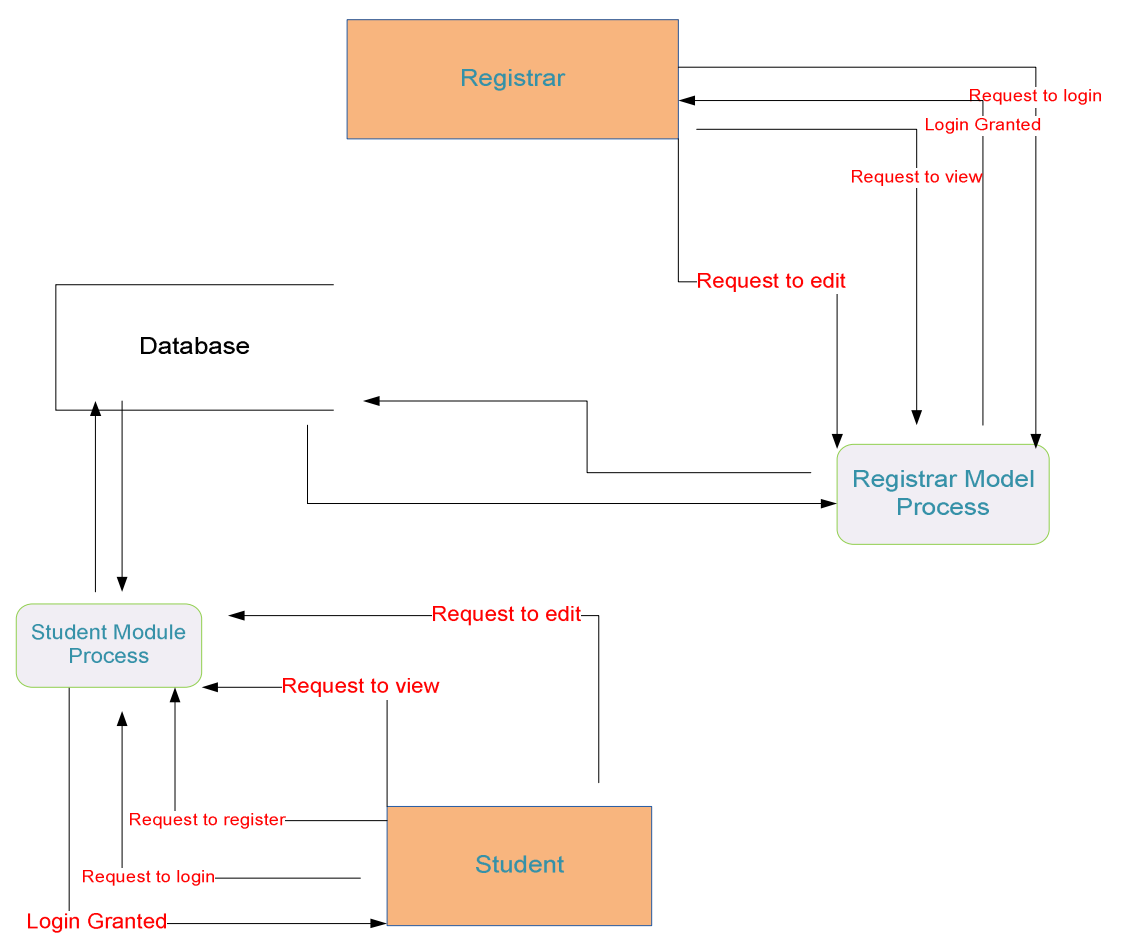

Fig 3.2. Dataflow Diagram

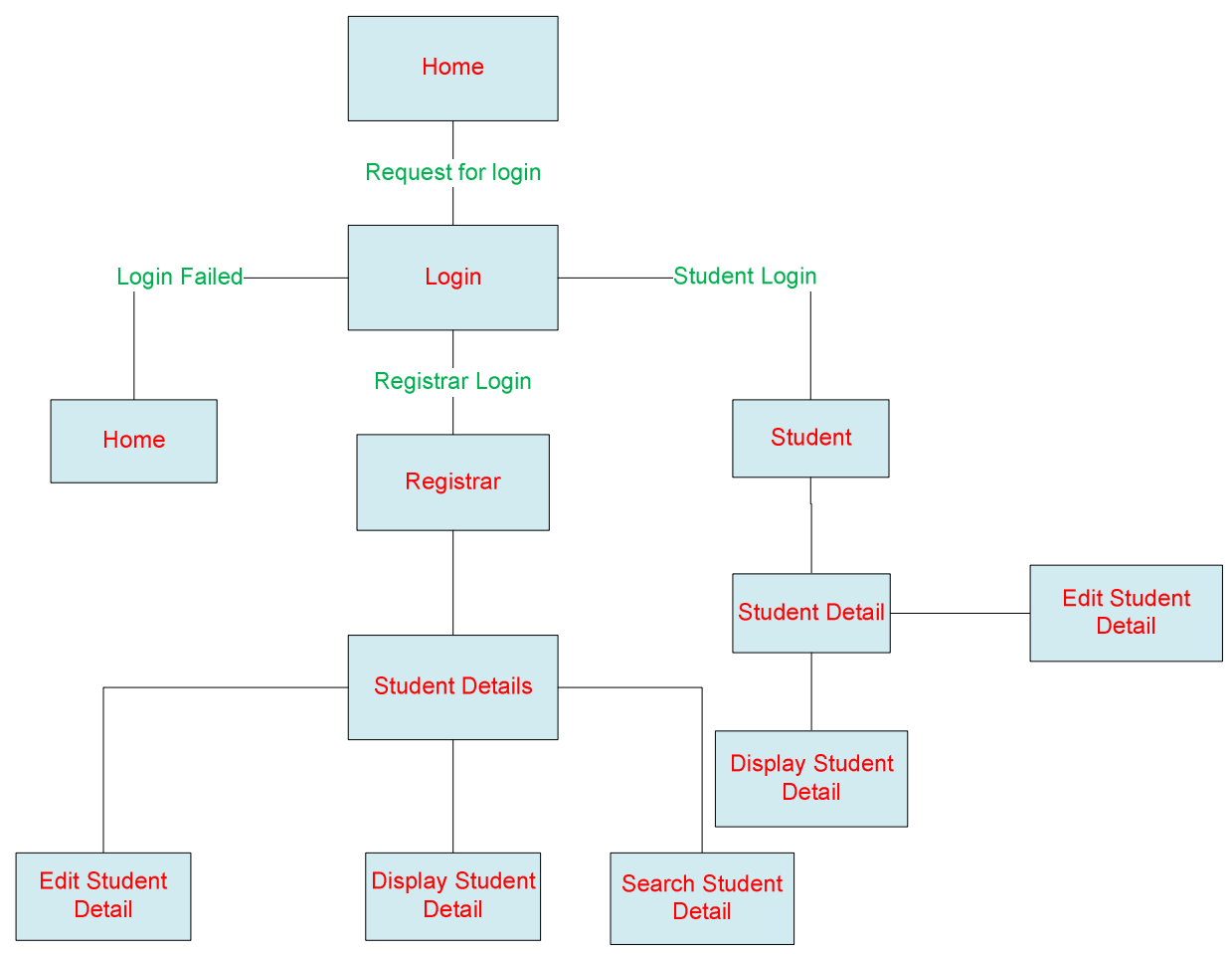

Fig 3.3. Decision Tree Diagram

Finally the design phase provides enough information with respect to all the entities and their relations.

\subsection{Technology Overview}

The technology selected for implementing Student Database System is PHP/MYSQL. Apache is used as the HTTP server.

\subsubsection{PHP}

PHP is a general-purpose scripting language that is especially suited to server-side web development where PHP generally runs on server. PHP code is embedded into HTML source document. Any PHP code is a requested file executed by the PHP runtime, usually to create dynamic web page content. It can also be used for command-line scripting and 
client-side graphical user interface (GUI) applications. PHP can be deployed on many web servers and operating systems, and can be used with many relational database management systems (RDBMS). It is available free of charge, and the PHP Group provides the complete source code for users to build, customize and extend for their own use.

\subsection{2. $M y S Q L$}

MySQL is a relational database management system (RDBMS) that runs as a server providing multi-user access to a number of databases. MySQL is a popular choice of database for use in web applications and is an open source product. The process of setting up a MySQL database varies from host to host, however we will end up with a database name, a user name and a password. Before using the database, a table must be created. A table is a section of the database for storing related information. In a table, different fields must be set up which will be used in the table. Table creation in phpMyAdmin is not difficult. SQL statement can also be executed to create databases and tables.

\subsubsection{Apache}

The Apache HTTP Server is web server software notable for playing a key role in the initial growth of the World Wide Web. In 2009 it became the first web server software to surpass the 100 million web site milestone. Apache is developed and maintained by an open community of developers under the auspices of the Apache Software Foundation. Since April 1996 Apache has been the most popular HTTP server software in use. As of November 2010 Apache served over $59.36 \%$ of all websites and over $66.56 \%$ of the first one million busiest websites.

\subsubsection{XAMPP}

XAMPP is a small and light Apache distribution containing the most common web development technologies in a single package. Its contents, small size, and portability make it the ideal tool for students developing and testing applications in PHP and MySQL. XAMPP is available as a free download in two specific packages: full and lite. While the full package download provides a wide array of development tools, XAMPP Lite contains the necessary technologies that meet the Ontario Skills Competition standards. The light version is a small package containing Apache HTTP Server, PHP, MySQL, phpMyAdmin, Openssl, and SQLite.

\section{Result}

A web based student database system intended to track and store student records is the outcome of the project after a critical analysis, design, building and testing of the system. Evaluation was properly done to ensure that the system meet all the requirements and specifications.

A stringent plan to monitor the implementation of the new system is laid-out and the entire project documented. Finally, the new system is deployed and users will receive some training to understand the new system. The new system would run alongside the old system until the new system is proven to be effective and efficient.

\subsection{Technologies Used}

HTML, CSS and PHP programming language are used to create an interface that allows the front end user to interact freely with the system. PHP is an object oriented programming language and it is flexible and user friendly because it allows the software developer to design the system with less code using Cascading Style Sheet (CSS), manipulate and graphically design the system. PHP is an HTML-embedded scripting language and is very powerful behind the scenes scripting language that visitors would not see. When you visit the PHP webpage, the web server processes the PHP code. It then sees which part it needs to show to visitors (contents and pictures) and hide the other stuff (file operations math calculations, etc.) then translate the PHP to HTML. After the translation into HTML it sends the webpage to the visitor's web browser.

MySQL is also chosen to create the database for the back end user since it is extensively used third generation database management system.

\subsubsection{Steps Involved in Database Creation}

The following steps were followed to create the database in MySQL:

- Create the database file in PHPMyADMIN

- Create a table in PHPMyADMIN

- Set up different fields which will be used in the table

- Insert dummy data into table

- Browse to view records in the table

\subsubsection{Forms Creation and Connection to the Database}

HTML is used to create the forms and the 'filename.php 'file created will process the HTML form information.

Before data can be accessed in a database, a connection to the database must be created. In PHP this is done with MySQL_Connect() function.

For example:

$<$ ? php

\$con=mysql_connect ("localhost", "root",,")

If(! \$con)

//Some data here

\{

Die ('could not connect'.mysql_eror(());

\}

?>

The example above is a simple PHP script used to connect to the MySQL database server. The die part will be executed if the connection fails.

\subsubsection{Hardware Requirements}

- Processor: Pentium IV

- Ram: 512 MB RAM

- Hard Disk: 80 GB Hard disk

\subsubsection{Software Requirements}

- Operating System: Microsoft XP/VISTA

- Database: Mysql database Server 


\section{- Application Software: Hypertext Preprocessor(PHP)}

\subsection{Linking Internal Database to the Web}

A series of middleware and other software products has been developed to help users gain access to organization's legacy data through the web. For example, a user with a web browser might want to search the web based student database for student information.

The figure below illustrates how the user might access the database over the web. The user would access the student database website over the internet using web browser on his or her personal computer. The user's browser would request data from the student database, using HTML commands to communicate with the web server. Because many back-end databases cannot interpret commands written in HTML, the web server would pass this request for data to special software that translate HTML commands into SQL so that they could be processed by the DBMS working with the database. The DBMS receives the SQL request and provides the required data. The figure also shows that the middleware working between the web server and the DBMS is an application server running on the dedicated computer.

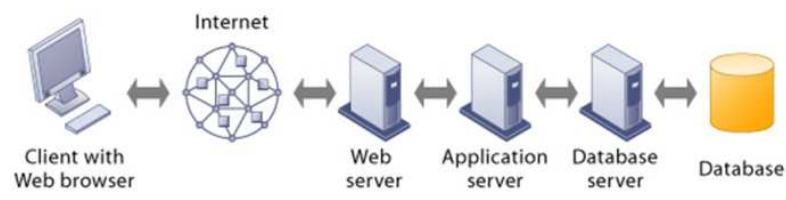

Fig 4. Linking internal database to the web.

\subsection{Implementation}

Implementation includes all the activities that take place to convert from the old system to the new. A proper implementation is required to provide a dependable system to meet the requirements. An improper installation may affect the success of the automated system. The most appropriate approach used was to run the old and new system in parallel. This offers high security, because even if there is a flaw in the automated system, the manual system can be depended on.

\subsection{How to Access the System}

- Mozilla or Internet Explorer can be used to access the web based student database system

- Follow the steps below to access the homepage:

- The page can be displayed by typing the URL address in the address field on the browser.

- The system has three type of accessing modes, registrar, student and head of department.

- Valid password and login Id are required on the login page to access the system

\subsection{Testing}

Thorough testing was done to ensure that the system produces the right results. It was time consuming to test the system because data must be carefully prepared, results reviewed and corrections made in the system.

\subsection{Maintenance}

The system will be maintained periodically through effective monitory and evaluation. This will go a long way to help identify and debug emergency production problems and address them accordingly. A considerable amount of time would be spent to effect changes in data, files, reports, hardware and software.

\section{Conclusion}

Information is an indispensable tool many schools and other organization use to advance decision making. Large amount of student's data are generated either manually or electronically on daily basis.

When population of student in a school is less than a hundred, the manual system can work perfectly but it is not the best method of managing records of students. The manual and disintegrated electronic systems have numerous disadvantages because these methods of capturing and managing data about students are prone to data inconsistency, data redundancy, difficult to update and maintain data, bad security, difficult to impose constraint on various data file and difficult to backup.

An integrated student database system provides prudent solutions to address problems associated with manual system. In order to assess the performance of the school and students overtime, there is the need to use past records of students without any missing data. The integrated student database system which captures and maintains longitudinal data of students would provide an accurate and reliable data about current and past students.

The system is free of errors and very efficient and less time consuming due to the care taken to develop it. All the phases of software development cycle are employed and it is worthwhile to state that the system is very robust. Provision is made for future development in the system.

\subsection{Recommendation}

Since student database system is very broad, the scope of this project covers only a small aspect of student information system due to the fact that the stipulated three month within which the project is expected to be executed is too short.

Students who are interested in building database system should be encouraged to work on other aspect of student information system in that all the available related student database system could be linked together.

The department of biostatistics should add programming to the courses offered and it should be made compulsory and run for both semesters. Health informatics students should be encouraged to work in a team to develop a software application system so that they will be well equipped with database and programming skills. This move will go a long way to help them do their project without any difficulty.

This report could be useful to any person who wants to do a project on similar topic. 


\section{Appendix A}

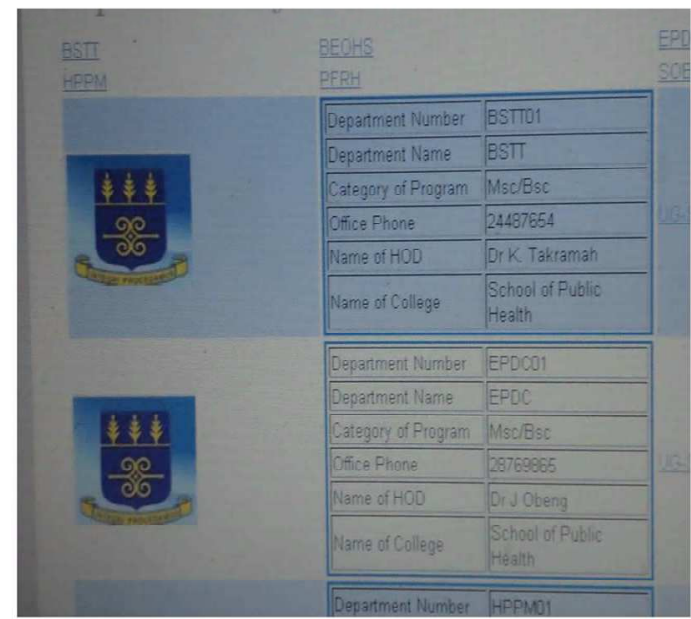

Fig 1. Department Details

\section{Appendix B}

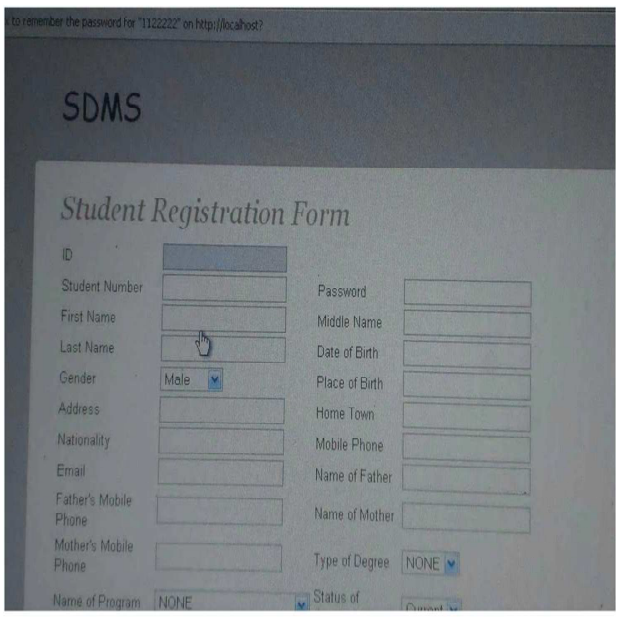

Fig 2. Student Registration Form

\section{Appendix C}

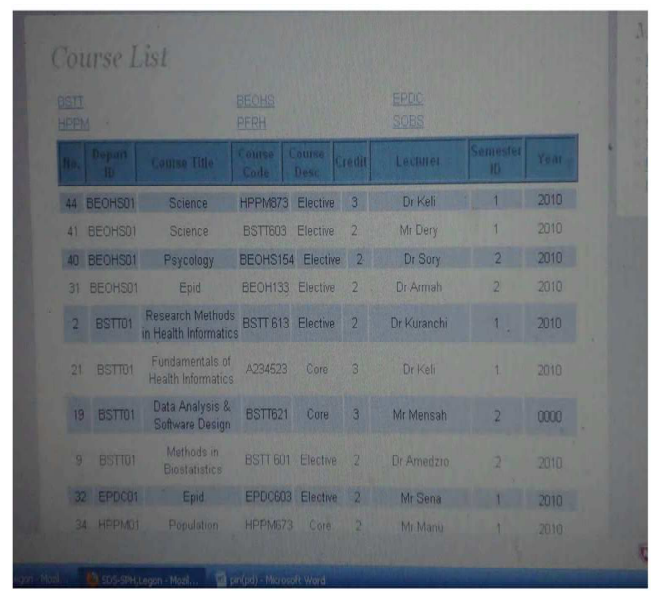

Fig 3. Course List Page

\section{Appendix D}

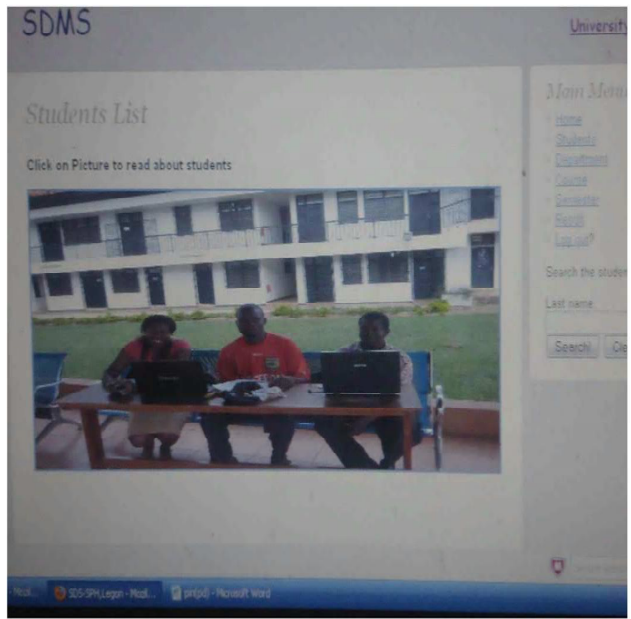

Fig 4. Student List Page

\section{Appendix E}

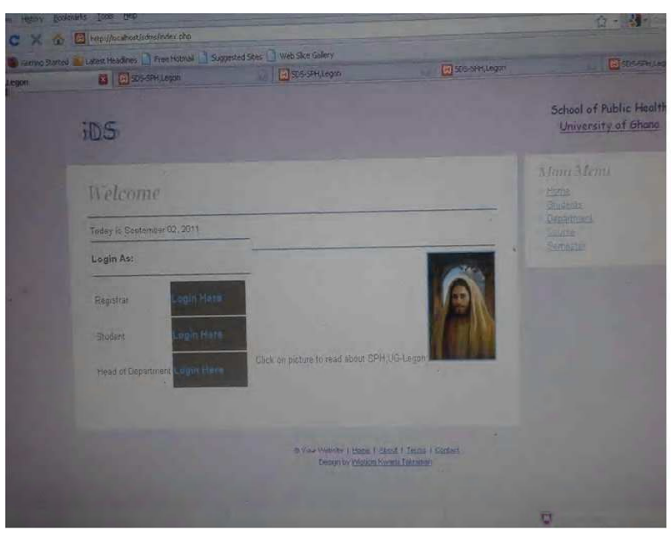

Fig 5. Home Page for Student Database System

\section{References}

[1] Connolly, T.M. and C.E. Begg, 2004. Database System: A Practical Approach to Design, Implementation and Management. 4rd Edn., Addison Wesley; ISBN: 10: 0321210255, pp: 1236

[2] Adams, C., Beath, C. M, Bolan, R., Branin, J., D'Elia, G., Rhode, N.L. \& Straub, D. 1991. Issues Relating to the Implementation and Management of an Integrated Information Centre. Journal of the American Society for Information Science.

[3] Adman, P. \& Warren, L. 1996. Information systems management: Perspectives for Higher Education. Lancs: Mir Press

[4] Angell, I. O. \& Smithson, S. 1991. Information Systems management: Opportunities and Risks. London: Macmillan Education Ltd.

[5] Association for the Development of Education in African. 2001. Technology as a Management Tool: A New Approach and Implementation. http//www.technologia.org/ [accessed on 23rd May 2011]. 
[6] Greenwald, R., R. Stackowiak, G. Dodge, D. Klein, B. Shapiro and C.G. Ghelliah, 2005. Professional Oracle Programming. Wrox, ISBN: 10: 0764574825, pp: 790

[7] Blaha M Rumbaugh 2005 (2nd ed.) Object-Oriented Modeling and Design with UML. [Basically this is the second edition of Rumbaugh et al 1991]. Prentice Hall

[8] Fry B. G. 1997. The Family Educational Rights and Privacy Act of 1974. In Student Records Management, edited by M Theresa Ruzicka and Beth Lee WeckMulle. London: Greenwood Press, 43-76.

[9] Higgins, J.C. 1976. Information Systems for Planning and Control: Concepts and Cases. London: Edward Arnold.

[10] Husain, K.M. 1977. Information Systems: Basic Concepts, Management Information Systems for Higher Education. Paris: The Organization for Economic Co-operation and Development.

[11] Gerald, C.O. 2009. Database Management System. Nigeria National Open University.

[12] Kroenke, D. \& Hatach, R. 1994. Management Information Systems, 3rd edition. New York: McGraw-Hill.
[13] Oliver, R. (2000). Creating Meaningful Contexts for Learning in Web-based Settings. Proceedings of Open Learning 2000. (pp 53-62). Brisbane: Learning Network, Queensland.

[14] Jonassen, D. \& Reeves, T. (1996). Learning with technology: Using computers as cognitive tools. In D. Jonassen (Ed.), Handbook of Research Educational on Educational Communications and Technology (pp 693-719). New York: Macmillan.

[15] Lebow, D. (1993). Constructivist values for instructional systems design: Five principles toward a new mind set. Educational Technology, Research and Development, 41(3), 4-16.

[16] Berners-Lee, T. J. 1992. "World-Wide Web: Information Universe", Electronic: Research, Applications and Policy. www.w3.org/People/Berners-Lee/Longer.html [accessed on 24th May 2011]

[17] Collis, B. (2002). Information technologies for education and training. In Adelsberger, H., Collis, B, \& Pawlowski, J. (Eds.) Handbook on Technologies for Information and Training. Berlin: Springer Verlag. 